\title{
Hubungan Persepsi Orang Tua Tentang Dampak Smartphone Terhadap Perkembangan Sosial Pada Anak Di Kelompok Bermain Gugus I Kecamatan Nanggalo Kota Padang
}

\author{
Annisa \\ ichaannisa236@yahoo.co.id
}

Serly Marlina

\section{Zulminiati}

\begin{abstract}
This study aims to determine the relationship between parents' perceptions of the impact of smartphone on social development in children in the Cluster I Group of Kecamatan Nanggalo. Parents today are mostly negligent towards their child's growth and development and rarely stimulate their children with social developmental issues and physical energy depletion and stimulating thinking and working together are no longer attractive. Freedom and freedom to play children have been seized by smartphones. This research includes a type of correlation research with quantitative methods with a total population of 30 people found in Cluster 1 in Kecamatan Nanggalo. The sampling technique is saturated sampling. The instrument used is a questionnaire. The results showed that the significance of $0,000>0,05$ and the coefficient of determination of the relationship of independent variables (parents' perception of the impact of smartphones) on the dependent variable (social development in children) was 55.3\%. It can be concluded that parents' perception of the impact of smartphones has a relationship to social development in children.
\end{abstract}

Keywords: Smartphone, Social Development

\section{PENDAHULUAN}

Anak usia dini adalah anak usia $0-8$ tahun yang berada pada masa pertumbuhan dan perkembangan sangat pesat atau lebih dikenal dengan masa golden age atau generasi emas. Masa ini merupakan masa yang tepat untuk meletakkan dasar-dasar pengembangan anak yaitu pengembangan fisik motorik, bahasa, sosial emosional, kognitif. Sehingga upaya pengembangan seluruh potensi anak usia dini harus di mulai agar pertumbuhan dan perkembangan anak tercapai secara optimal.

Dalam mengembangkan pontesipotensi anak harus melibatkan peran orang tua yang merupakan ayah dan ibu seorang anak, baik melalui hubungan biologis maupun sosial. Orang tua memiliki peranan yang sangat penting dalam membesarkan, mendidik dan membimbing anak. Tugas orang tua melengkapi kebutuhan, menfasilitasi dan mempersiapkan anak menuju ke kedewasaan dengan memberikan bimbingan dan pengarahan yang dapat membantu anak dalam menjalani kehidupan.

Salah satu fasilitas yang diberikan orang tua pada zaman modern sekarang adalah smartphone. Menurut Rahmawati dalam Mubara (2017:14) mengatakan telepon pintar atau yang lebih populer 
dengan sebutan smartphone adalah telepon genggam berbentuk mini dengan fungsi menyerupai komputer. Alat komunikasi canggih yang bisa di bawa kemana saja tersebut sudah terhubung dengan koneksi internet. Fitur yang disediakan pun beragam sehingga membuat kita bisa mudah menjelajahi pelosok dunia, yaitu melalui Facebook, Twitter, Instagram, dan lain-lain.

Orang tua berpikir dengan memberikan anaknya sebuah smartphone anak bisa menjadi penurut, tidak menangis lagi dan sebagai ajang untuk memamerkan anaknya bisa mengotak-atik smarphone. Apalagi kepada anak usia 3-4 tahun, orang tua selalu memberi anak smarphone supaya anak tidak menangis dan menganggu orang tua. Tetapi orangtua tidak memikirkan dampak smarphone kepada anak. menurut Rahmawati dalam Mubara (2017:21-32) dampak penggunaan smarphone yaitu : menghambat kecerdasan emosional, risiko terpapar radiasi, nyeri leher dan perubahan anatomi tulang, hambatan terhadap perkembangan, lambat memahami pelajaran, berisiko terhadap perkembangan psikologi anak, perubahan perilaku anak.

Penggunaan smartphone yang bijaksana akan memberikan dampak positif bagi perkembangan sosial anak di usia dini dalam pertumbuhannya. Orang tua sangat berperan vital mendampingi buah hati saat menggunakan smartphone. Bila orang tua telah berhasil membuat kesepakatan dengan anak tentang peraturan bermain smartphone, kemudian bisa membuat jadwal harian, menentukan jam boleh bermain smartphone dan seterusnya, maka inilah saat yang aman untuk menggunakan gawai atau gadget.

Jika anak terfokus pada smartphone akan mempengaruhi perkembangan sosial anak untuk beradaptasi dengan orang lain. Menurut Trianto (2011:19), menyatakan perkembangan sosial mengikuti suatu pola, yaitu suatu urutan perilaku sosial. Pola ini sama pada semua anak di dalam suatu kelompok budaya. Maka, ada pola sikap anak tentang minat terhadap aktivitas sosial dan pilihan teman.

Kenyataan di lapangan yang peneliti temukan orang tua di Kelompok Bermain Gugus I Kecamatan Nanggalo Kota Padang adalah orang tua yang berkerja pada umumnya, peranan ibu dan ayah tentulah sangat berbeda. Oleh karena itu banyak anak usia dini di Kelompok Bermain Gugus I Kecamatan Nanggalo banyak yang kurang diperhatikan oleh orang tuanya. Orang tua saat ini kebanyakan lalai terhadap tumbuh kembang anaknya dan jarang menstimulasi anaknya dengan hal-hal perkembangan sosial pada ank dan fisik yang menguras energi serta merangsang berpikir dan bekerja sama kini tidak lagi menarik. Kebebasan dan kemerdekaan bermain anak berhasil dirampas oleh smartphone.

Dapat dilihat bahwa generasi penerus bangsa yakni anak-anak telah di rusak oleh zaman modren saat ini dan menimbulkan generasi tidak baik untuk bangsa ini. Hal ini harus di antisipasi oleh orang tua agar anakanak tidak lagi kecanduan dengan smartphone dan berikan anak peraturan bermain dan jadwal yang tepat dalam penggunaan smartphone dan sangat perlu didampingi oleh orang tua. Agar perkembangan sosial anak tidak lagi dirampas oleh smartphone tersebut.

Berdasarkan uraian tersebut di atas, peneliti tertarik melakukan penelitian di wilayah Kelompok Bermain Gugus I Kecamatan Nanggalo Kota Padang karena persepsi orang tua mengenai dampak smartphone terhadap perkembangan sosial anak dalam mendampingi buah hati saat menggunakan smartphone. Itu akan memberikan dampak negatif bagi perkembangan sosial anak di usia penting pertumbuhannya. Karena orang tua yang terlalu sibuk, orang tua lebih baik memberikan smartphone kepada anak dari pada anak bermain di luar rumah. Atas 
dasar fenomena tersebut mendorong peneliti untuk melakukan penelitian dengan judul : "Hubungan Persepsi Orang Tua Tentang Dampak Smartphone Terhadap Perkembangan Sosial Pada Anak Di Kelompok Bermain Gugus I Kecamatan Nanggalo Kota Padang".

\section{METODE PENELITIAN}

Penelitian ini termasuk jenis penelitian korelasional dengan metode kuantitatif (Arikunto, 2014; Sugiyono, 2007). Penelitian korelasi menurut Sukardi (2012:166) adalah suatu penelitian yang melibatkan tindakan pengumpulan data guna menentukan, apakah ada hubungan dan tingkat hubungan antara dua variabel atau lebih. Populasi dari penelitian ini yaitu orang tua yang mempunyai anak yang berusia 3 sampai 4 tahun di Kelurahan Gurun Laweh sebanyak 30 orang.

Sampel yang akan diambil menggunakan teknik Sampling Jenuh. Menurut Sugiyono (2015:156), Sampling Jenuh ialah penentuan pengambilan sampel bila semua anggota populasi digunakan sebagai sampel. Instrumen yang digunakan adalah angket dengan jenis Skala Likert. Menurut Sugiyono (2007) skala likert digunakan untuk mengukur sikap, pendapat, dan persepsi seseorang atau sekelompok orang tentang fenomena sosial.

Teknik analisis data menggunakan pengujian persyaratan dan hipotesis. Penguji persyaratan terdiri dari uji validitas bertujuan untuk menunjukkan tingkattingkat kevalidan instrumen, uji reliabitas untuk mengetahui instrumen dapat dipercaya atau tidak, uji normalitas untuk mengetaui apakah data berasal dari populasi berdistribusi normal setelah itu baru dilakukan uji linearitas bertujuan untuk mengetahui hubungan antara variabel $X$ dengan variabel $Y$ liner atau tidak. Kemudian dilakukan pengujian hipotesis digunakan untuk melihat hubungan persepsi orang tua tentang dampak smartphone (variabel bebas) terhadap perkembangan sosial pada anak (variabel terikat) digunakan rumus koefisien korelasi product moment dengan menggunakan bantuan SPSS Versi 23.

\section{HASIL DAN PEMBAHASAN Hasil}

Analisis deskriptif digunakan untuk menjelaskan karakteristik responden penelitian. Hal ini sejalan dan terinspirasi oleh penelitian relevan yang sebelumnya dilakukan oleh Hermawan (2015), Syaputra (2019), Wiyoko (2019). Dalam analisis ini akan menginterprestasikan data dan jawaban yang diberikan responden terhadap karakteristik responden yaitu orang tua pada Kelompok Bermain Gugus I Kecamatan Nanggalo Kota Padang. Hal ini dilakukan untuk menganalisis demografi responden berdasarkan kriteria yang telah ditentukan seperti jenis kelamin, usia, dan pendidikan terakhir. Pada penelitian ini terdapat 30 kuesioner yang disebarkan kepada 30 orang responden.

Untuk dapat menarik hasil kesimpulan penelitian uji hipotesisi, sebelum melakukan uji hipotesis terlebih dahulu melalukan uji normalitas parametric one sample Kolmogrov Smirnov test. Sebuah variabel dinyatakan normal apabila menghasilkan nilai Asymp Sig > alpha 0,05. Berdasarkan seperti terlihat pada tabel 1 yang bisa terlihat pada teks setelah ini : 
Tabel 1. Hasil Uji Normalitas One-Sample KolmogorovSmirnov Test

\begin{tabular}{llr}
\hline & & \multicolumn{1}{c}{$\begin{array}{c}\text { Unstandardize } \\
\text { d Residual }\end{array}$} \\
\hline $\mathbf{N}$ & & 30 \\
\hline $\begin{array}{l}\text { Normal } \\
\text { Parameters } \\
\text { a,b }\end{array}$ & Mean &, 0000000 \\
\cline { 2 - 3 } & Std. Deviation & 4,76789290 \\
\hline $\begin{array}{l}\text { Most } \\
\text { Extreme } \\
\text { Differences }\end{array}$ & Absolute &, 109 \\
\cline { 2 - 3 } & Positive &, 109 \\
\cline { 2 - 3 } & Negative &,- 041 \\
\hline Test Statistic & &, 109 \\
\hline Asymp. Sig. (2-tailed) &, $200^{c, d}$ \\
\hline Sumber : SPSS Versi 23.0 dan data primer diolah, 2018
\end{tabular}

Berdasarkan hasil tabel 1 di atas uji normalitas diketahui nilai signifikansi 0,200 $>0,05$, maka dapat disimpulkan bahwa nilai residual berdistribusi normal.

Kemudian dilakukan uji Linearitas dilakukan dengan dasar pengambilan keputusan data jika nilai signifikan deviation from linearity $>0,05$, maka terdapat hubungan yang linear antara variabel bebas dengan variabel terikat. Berdasarkan hasil pengujian linearitas antara variabel bebas dan variabel terikat dapat dilihat pada tabel 2 berikut :

Tabel 2. Hasil Uji Linearitas ANOVA Table

\begin{tabular}{|c|c|c|c|c|c|c|c|}
\hline & & & $\begin{array}{l}\text { Sum of } \\
\text { Squares }\end{array}$ & df & $\begin{array}{l}\text { Mean } \\
\text { Square }\end{array}$ & $\mathbf{F}$ & $\begin{array}{l}\text { Si } \\
\text { g. }\end{array}$ \\
\hline \multirow{2}{*}{$\begin{array}{l}\text { Perkemba } \\
\text { ngan }\end{array}$} & 3etween & (Combin & 1451,800 & 23 & 63,122 & 16 , & 0 \\
\hline & Groups & ed) & & & & 34 & 01 \\
\hline \multicolumn{2}{|l|}{ Sosial } & & & & & 8 & \\
\hline & Linearity & 815,715 & 1 & 815,71 & 21 & 0 \\
\hline \multicolumn{2}{|l|}{ * Persepsi } & & & & 5 & 1,2 & 00 \\
\hline \multicolumn{2}{|l|}{ Orang Tua } & & & & & 64 & \\
\hline \multirow{5}{*}{$\begin{array}{l}\text { Tentang } \\
\text { Dampak } \\
\text { Smartphon } \\
e\end{array}$} & & Deviatio & 636,085 & 22 & 28,913 & 7,4 & 0 \\
\hline & & $\mathrm{n}$ from & & & & 88 & 10 \\
\hline & & Linearity & & & & & \\
\hline & Within & oups & 23,167 & 6 & 3,861 & & \\
\hline & Total & & 1474,967 & 29 & & & \\
\hline
\end{tabular}

Berdasarkan tabel 2 diatas terlihat nilai signifikan deviation from linearity sebesar $0,010>0,05$, maka dapat disimpulkan bahwa terdapat hubungan yang linear antara Persepsi Orang Tua Tentang Dampak Smartphone dengan Perkembangan Sosial Pada Anak. Atau diketahui nilai Fhitung 7,488 > Ftabel 2,42, sehingga dapat disimpulkan bahwa tidak terdapat hubungan yang linear antara Persepsi Orang Tua Tentang Dampak Smartrphone dengan Perkembangan Sosial Pada Anak.

Selanjutnya melakukan pengujian hipotesis digunakan rumus koefisien korelasi product moment dengan menggunakan bantuan SPSS Versi 23 Uji t yang dimaksud untuk menguji signifikan hubungan variabel bebas dan terikat secara parsial, dimana pengujian ini membandingkan antara protabilitas signifikan dengan alpha 0,05. Dari hasil pengujian ini bila protabilitas signifikan lebih kecil dari alpha 0,005, maka diperoleh Ho di tolak dan Ha diterima, berarti ada hubungan antara dn bila protabilitas signifikan lebih besar dari pada 0,05 maka Ho diterima dan Ha ditolak, berarti tidak ada hubungan. Derajat kebebasan (df) n-k-1 yaitu $\quad 30-1-1=28$ (n adalah jumlah responden dan $\mathrm{k}$ adalah jumlah variabel independen). Analisi regresi linear sederhana digunakan untuk melihat pengaruh variabel independen yaitu persepsi orang tua tentang dampak smartphone secara parsial terhadap variabel dependen yaitu perkembangan sosial pada anak dengan asumsi independen lain dianggap konstan.

Tabel 3. Hasil Analisis Korelasi

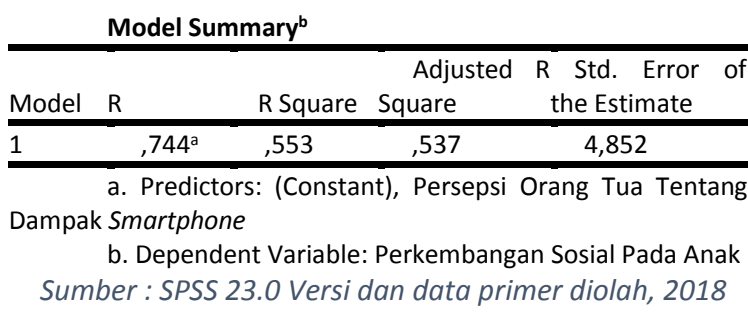

Berdasarkan tabel 3 di atas dapat disimpulkan bahwa besarnya nilai korelasi/hubungan $(R)$ yaitu sebesar 0,744. 
Dari data yang diperoleh koefisien determinasi (R Square) sebesar 0,553, yang mengandung pengertian bahwa hubungan variabel bebas (persepsi orang tua tentang dampak smartphone) terhadap variabel terikat (perkembangan sosial pada anak) adalah sebesar $55,3 \%$.

Tabel 4. Hasil Regresi Sederhana Variabel Persepsi Orang Tua Tentang Dampak Smartphone (X) Terhadap Perkembangan Sosial Pada Anak (Y)

Coefficients

\begin{tabular}{|c|c|c|c|c|c|c|}
\hline \multirow[b]{2}{*}{ Model } & \multicolumn{2}{|c|}{$\begin{array}{l}\text { Unstandardized } \\
\text { Coefficients }\end{array}$} & $\begin{array}{l}\text { Standardized } \\
\text { Coefficients }\end{array}$ & & & \multirow[b]{2}{*}{ Sig. } \\
\hline & B & $\begin{array}{l}\text { Std. } \\
\text { Error }\end{array}$ & Beta & & & \\
\hline (Constant) & 9,513 & 4,581 & & ,077 & 7 &, 04 \\
\hline \multicolumn{2}{|c|}{$\begin{array}{l}\text { Persepsi orangtua } \\
\text { tentang dampak, } 544 \\
\text { smartphone }\end{array}$} & ,092 & 744 & ,886 & 0 & ,00 \\
\hline
\end{tabular}

a. Dependent Variable: Perkembangan Sosial Pada Anak Sumber : SPSS 23.0 Versi dan data primer diolah, 2018

Dari persamaan regresi linear sederhana dalam tabel 4, dapat disimpulkan bahwa nilai konstan sebesar 9,513 artinya apabila persepsi orang tua tentang dampak smartphone diabaikan (0), maka perkembangan sosial pada anak nilainya sebesar 9,513 sedangkan koefisien persepsi orang tua tentang dampak smartphone sebesar 0,544 artinya apabila persepsi orang tua tentang dampak smartphone dinaikkan satu (1) satuan maka nilai perkembangan sosial akan mengalami kenaikan sebesar 0,544.

Tabel 5. Pengujian Hipotesis Atas Semua Variabel $X$ dan $Y$

\begin{tabular}{|c|c|c|c|c|c|}
\hline No & Variabel & t hitung & t tabel & Sig & Keterangan \\
\hline \multirow[t]{6}{*}{1} & Persepsi & 5,886 & 2,048 & 0,00 & $\mathrm{H}_{\mathrm{o}}$ ditolak, $\mathrm{H}_{\mathrm{a}}$ \\
\hline & Orang Tua & & & 0 & diterima \\
\hline & Tentang & & & & \\
\hline & Dampak & & & & \\
\hline & Smartphon & & & & \\
\hline & $e$ & & & & \\
\hline
\end{tabular}

Sumber: SPSS 23.0 Versi dan data primer diolah, 2018

Berdasarkan tabel 5 di atas maka dapat disimpulkan bahwa thitung $>$ ttabel $(5,886>2,048)$ dengan signifikansi $(0,000<$ $0,05)$, artinya secara parsial berpengaruh signifikan antara persepsi orang tua tentang dampak smartphone dengan perkembangan sosial pada anak. Dengan demikian Ho ditolak dan $\mathrm{Ha}$ diterima. Sehingga dapat disimpulkan bahwa variabel persepsi orang tua tentang dampak smartphone $(X)$ berhubungan terhadap variabel perkembangan sosial pada anak (Y).

\section{Pembahasan}

Berdasarkan hasil penelitian di Kelompok Bermain Gugus I Kecamatan Nanggalo Kota Padang, ditemukan bahwa terdapat hubungan persepsi orang tua tentang dampak smartphone terhadap perkembangan sosial pada anak hal ini terbukti bahwa persepsi orang tua tentang dampak smartphone terhadap perkembangan sosial pada anak, seperti penurunan konsentrasi saat belajar, malas menulis dan membaca, penurunan dalam kemampuan bersosialisasi, membangun kerjasama, memahami adanya perbedaan perasaan, dan meminjam dan meminjamkan mainan.

Hasil temuan peneliti di Kelompok Bermain Gugus I Kecamatan Nanggalo Kota Padang mengenai korelasi antara persepsi orang tua tentang dampak smartphone berhubungan terhadap perkembangan sosial pada anak sebesar 0,744 dan koefisien determinasinya sebesar 0,553 . Hal ini berarti persepsi orang tua tentang dampak smartphone sebesar 55,3\% terhadap perkembangan sosial pada anak di Kelompok Bermain Gugus I Kecamatan Nanggalo Kota Padang pada taraf 5\%. Dapat dikatakan bahwa persepsi orang tua tentang dampak smartphone mempunyai hubungan yang cukup besar terhadap perkembangan sosial pada anak di Kelompok Bermain Gugus I Kecamatan Nanggalo Kota Padang sebesar 55,3\%.

Hasil analisis di atas dinyatakan bahwa jika tidak dilakukan pengontrolan terhadap dampak lain, maka persepsi orang tua tentang dampak smartphone terhadap perkembangan sosial pada anak sebesar 
$55,3 \%$ dan selebihnya $44,7 \%$ lagi disebabkan oleh dampak lainnya.

Hasil analisis data reliabilitas terlihat instrumen berdasarkan analisis reliabilitas atas variabel adalah di atas 0,6, untuk itu seluruh variabel bisa dikatakan reliabel (handal). Bahwa variabel persepsi orang tua tentang dampak smartphone memiliki realibilias tes sangat tinggi dengan nilai Cronbach alpha sebesar 0,868 lebih di atas 0,6 dan perkembangan sosial pada anak juga memiliki realibilias tes sangat tinggi dengan nilai Cronbach alpha sebesar 0,846 lebih di atas 0,6. Jadi hubungan persepsi orang tua tentang dampak smartphone terhadap perkembangan sosial pada anak terdapat hubungan reliabel yang sangat tinggi.

Hasil penelitian ini sesuai dengan teori yang telah dikemukan oleh para ahli dampak smartphone dan perkembangan sosial Menurut Noegroho dalam Rohmah (2018:418), mengidentifikasi beberapa dampak negatif gadget pada anak adalah : a) penurunan konsentrasi saat belajar, b) malas menulis dan membaca menurut Andari dalam Radliya (2017:4), serta c) penurunan dalam kemampuan bersosialisasi menurut Febrino (2017:7). Dan sejalan dengan itu, standar isi tentang tingkat pencapaian perkembangan anak usia 3-4 tahun yaitu: Perilaku Prososial yaitu : 1) membangun kerjasama menurut Nurmalitasari (2015:105), 2) memahami adanya perbedaan perasaan (teman takut, saya tidak) menurut Nurmalitasari (2015:105), 3) meminjam dan meminjamkan mainan menurut Peraturan Menteri Pendidikan dan Kebudayaan Republik Indonesia Nomor 137 Tahun 2014 tentang Standar Nasional Pendidikan Anak Usia Dini. Oleh karena itu bagaimana orang tua mengatur, mengontrol dan mendampingi anak agar smartphone tidak berdampak negatif terhadap perkembangan sosial anak. Sejalan dengan penelitian ini, beberapa penelitian juga menyebutkan bahwa korelasi positif juga ditemukan dalam penelitian oleh Kusumah \& Munandar (2017) yang menyatakan bahwa hasil belajar juga dipengaruhi oleh beberapa sikap yang mendukung dalam motivasi belajar dan kesadaran akan keberadaan dirinya dalam lingkungan pendidikan.

Berdasarkan hasil penelitian tersebut persepsi orang tua tentang dampak smartphone memiliki hubungan terhadap perkembangan sosial pada anak. Apabila orang tua tidak memberikan smartphone sepenuhnya dengan anak, maka tidak akan berdampak negatif pada perkembangan sosial anak. Namun setelah peneliti melakukan penelitian penyebaran angket peneliti menemukan realita bahwa, orang tua mengisi angket dengan memberikan tanda kalau anaknya tidak bermasalah dalam menggunakan smartphone. Sedangkan kenyataan yang peneliti lihat dan temukan bahwa jika anak sedang menggunakan smartphone maka anak tersebut tidak menghiraukan orang yang disekitarnya. Hal ini mengindikasikan bahwa orang tua berusaha untuk menutupi aib yang dimiliki oleh keluarganya. Walaupun pada pendahuluan penelitian telah diberikan pemahaman bahwa orang tua tidak akan diberitahukan kepada khalayak ramai mengenai identitasnya, namun tetap saja pada saat pengisian kuesioner orang tua berusaha menutupi kekurangan yang dimiliki oleh anaknya tersebut.

Melihat kenyataan ini sebaiknya kepada lembaga yang memiliki wewenang dan sebagainya sebaiknya memberikan parenting education atau sosialisasi kepada orang tua mengenai dampak penggunaan smartphone. Sehingga orang tua mengetahui dampak smartphone terhadap perkembangan anak dan bagaimana seharusnya orang tua memberikan smartphone kepada anak usia dini. Apabila orang tua mendampingi, mendidik, mengajarkan dan membuatkan peraturan 
dalam menggunakan smartphone pada anak, maka perkembangan sosial anak akan berkembangan dengan baik. Lembaga yang memiliki wewenang sebaiknya juga melakukan kegiatan seminar untuk para orang tua mengenai dampak gadget terhadap anak. Selain itu menjelaskan kegiatan fisik yang sebaiknya dilakukan sebanyak-banyaknya agar anak-anak bisa melupakan kegiatan yang dilakukan dengan gadget.

Perkembangan sosial anak akan berkembang dengan baik jika lingkungan di sekitarnya seperti di sekolah, rumah maupun di lingkungan bermainnya mendukung untuk tetap beraktifitas fisik (Amri \& Tharihk, 2018; KHOTIMAH, 2011; Wati, Saparahayuningsih, \& Yulidesni, 2017) - Sehingga dengan demikian aktifitas dengan menggunakan gadget ataupun smartphone dapat terlupakan. Hal ini bisa dicapai jika komponen yang terkait dengan siswa seperti orang tua, dan teman-teman mampu untuk membuat kegiatan fisik di lingkungan anak tersebut. Sejalan dengan penelitian yang dilakukan oleh Agustriana (2019) banyak sekali kegiatan yang bisa dilakukan untuk meningkatkan keterampilan sosial anak

\section{KESIMPULAN}

Dari pemaparan hasil penelitian di pembahasan dapat simpulkan bahwa terdapat korelasi yang positif antara penggunaan gadget dengan perkembangan social anak. Anak yang memiliki kecenderungan memegang gadget terlalu lama cenderung memiliki keterampilan sosial yang negatif. Hal ini bermakna bahwa, anak yang sering menggunakan gadget akan cenderung tidak menghiraukan keadaan lingkungan di sekitarnya dan memiliki ketidakinginan untuk bergaul dengan teman-teman sebayanya.

Penelitian ini melibatkan orang tua siswa sebagai responden, karena orang tua memiliki intensitas kedekatan yang lebih lama dengan anak-anak sehingga dengan mudah mengobservasi dan mengamati perilaku anak-anak setiap harinya. Sehingga orang tua bisa menyimpulkan sendiri kegiatan-kegiatan yang sekiranya baik untuk anak itu sendiri maupun untuk orang tua itu sendiri.

\section{DAFTAR PUSTAKA}

Agustriana, N. (2019). PENGARUH METODE EDUTAINMENT DAN IDENTITAS DIRI TERHADAP KETERAMPILAN SOSIAL ANAK. Al-Fitrah, 1(2), 216-228. Retrieved from

http://ejournal.iainbengkulu.ac.id/index .php/alfitrah/article/view/1517

Amri, A., \& Tharihk, A. J. (2018). PENGEMBANGAN PERANGKAT ASESMEN PEMBELAJARAN PROYEK PADA MATERI PENCEMARAN DAN KERUSAKAN LINGKUNGAN. DIDAKTIKA BIOLOGI: Jurnal Penelitian Pendidikan Biologi, 2(2), 103-112. Retrieved from http://jurnal.umpalembang.ac.id/dikbio/article/view/12 $83 / 1095$

Arikunto, S. (2014). Metode Penelitian Kuantitatif, Kualitatif, dan Kombinasi (Mixed Methods). Bandung: Alfabeta.

Hermawan, I. K. D. (2015). Kinerja Pendidikan Anak Usia Dini Dan Pendidikan Nonformal Berdasarkan Misi Pendidikan Performance of Early Childhood Education and Nonformal Edu- Cation Based on Education Mission. Jurnal Pendidikan Dan Kebudayaan, 21(1), 87-100. https://doi.org/http://dx.doi.org/10.2483 2/jpnk.v21i1.178

KHOTIMAH, D. R. K. (2011). HUBUNGAN FAKTOR LINGKUNGAN FISIK RUMAH DAN SUMBER PENCEMARAN DALAM 
RUMAH DENGAN KEJADIAN ISPA

PADA BALITA DI DESA BANGETAYU WETAN

KECAMATAN GENUK KOTA

SEMARANG. Semarang: Diponegoro University. Retrieved from http://eprints.undip.ac.id/33244/

Kusumah, R. G. T., \& Munandar, A. (2017). ANALYSIS OF THE RELATIONSHIP BETWEEN SELF EFFICACY AND HEALTHY LIVING CONCIOUSNESS TOWARD SCIENCE LEARNING OUTCOME. EDUSAINS, 9(2), 132-138. https://doi.org/10.15408/ES.V9I2.2183

Mubara, Kayla, dkk. 2017. Smartmom untuk Generasi Smart: Panduan Parenting di Era Digital. Yogyakarta : Diva Press

Permendikbud. 2014. Standar Nasional Pendidikan Anak Usia Dini. Jakarta : Permendikbud.

Radilya, dkk. 2017. Pengaruh Penggunaan Gawai Terhadap Perkembangan Sosial Emosional Anak Usia Dini. ejournal Pendidikan Anak Usia Dini UPI Tasikmalaya (Volume1 No. 1)

Rohmah, Umi. 2018. Gadget dan Perkembangan Sosial Anak Usia Dini. e-journal Pendidikan Anak Usia Dini IAIN Ponorogo (Volume 1, hal. 417430)

Sugiyono. (2007). Metode Penelitian Kualitatif, Kuantitatif dan $R \& D$. Bandung: Alfabeta.

Sugiyono. 2015. Metode Penelitian Kuantitatif, Kualitatif, dan $R \& D$. Bandung: ALFABETA

Sukardi. 2012. Metodologi Penelitian Pendidikan. Jakarta: PT Bumi Aksara

Syaputra, E. (2019). PANDANGAN GURU
TERHADAP

INTEGRASI

KEARIFAN LOKAL DALAM

PEMBELAJARAN SEJARAH:

STUDI DESKRIPTIF DI BEBERAPA

SMA DI BENGKULU SELATAN

DAN KAUR. IJSSE: Indonesian

Journal of Social Science Education, 1(1), 1-10. Retrieved from http://ejournal.iainbengkulu.ac.id/index .php/ijsse/article/view/1-10

Trianto. 2011. Desain Pengembangan Pembelajaran Tematik Bagi Anak Usia Dini TK/RA \& Anak Usia Kelas Awal SD/MI. Jakarta : Kencana.

Wati, K. I., Saparahayuningsih, S., \& Yulidesni, Y. (2017). Meningkatan Keterampilan Motorik Halus Anak Melalui Kegiatan Pembelajaran Membatik Menggunakan Media Tepung Pada Anak Kelompok B PAUD Aisyiyah III Kota Bengkulu. Jurnal Ilmiah POTENSIA, 2(2), 91-94. https://doi.org/10.33369/jip.2.2

Wiyoko, T. (2019). Analisis Profil Kemampuan Berpikir Kritis Mahasiswa PGSD Dengan Graded Response Models Pada Pembelajaran IPA. Indonesian J. Integr. Sci. Education ( IJIS Edu ), 1(1), 25-32. Retrieved from http://ejournal.iainbengkulu.ac.id/index .php/ijisedu 